\title{
Anthropometric factors have significant influence on the outcome of the GHRH-arginine test - establishment of normative data
}

Timo Deutschbein (1), Martin Bidlingmaier (2), Jochen Schopohl (2), Christian J. Strasburger (3), *Stephan Petersenn (4)

(1) Department of Internal Medicine I, Endocrine and Diabetes Unit, University Hospital Würzburg, University of Würzburg, Würzburg, Germany;

(2) Medizinische Klinik und Poliklinik IV, Klinikum der LMU München, Munich, Germany; (3) Department of Medicine for Endocrinology, Diabetes and Nutritional Medicine, Charité Universitätsmedizin, Campus Mitte, Berlin, Germany; (4) ENDOC Center for Endocrine Tumors, Hamburg, Germany

\section{Introduction and objectives}

The diagnosis of growth hormone (GH) deficiency (GHD) in adults is based on provocative testing of $\mathrm{GH}$ secretion.

The GHRH plus Arginine (GARG) test has been proposed as an alternative to the insulin tolerance test.

To improve the diagnostic accuracy of the GARG, we aimed to establish normative data applying a newly developed automatic immunoassay specifically measuring $22 \mathrm{kD} \mathrm{hGH}$.

\section{Methods}

$>$ Two hundred healthy subjects $(C)$ were prospectively stratified into three age groups $(18-30,31$ $50,>51$ years), three BMI groups $\left(<25,25-29.9,>=30 \mathrm{~kg} / \mathrm{m}^{2}\right)$, and for both sexes, with at least 10 subjects in each subgroup.

All subjects received GHRH $1 \mu \mathrm{g} / \mathrm{kg}$ i.v., followed by a 30-min infusion of L-ARG (30g), with blood samples drawn at 0', 30', 45', 60', 90', and 120'.

$>$ In addition, eighty-seven patients with hypothalamic-pituitary disease were studied by GHRHarginine test. Patients were classified according to the number of pituitary hormone deficiencies (PHD) and GHD was assumed when $\geq 2 \mathrm{PHD}$ (in addition to $\mathrm{GH}$ ) were present $(n=51)$; the remaining 36 patients with $<2 \mathrm{PHD}$ were considered $\mathrm{GH}$ sufficient (GHS).

GH was measured with a newly developed GH immunoassay (IDS iSYS, Boldon, UK).

$>$ ROC analysis was used to identify thresholds with at least $95 \%$ specificity.

\section{Results}

Influence of age, BMI, and sex on GH peak levels in healthy subjects.

$>$ Multiple stepwise regression analysis in controls revealed that both BMI $(21 \%, p<0.0001)$ and sex $(20 \%, p<0.0001)$ accounted for most of the variability of $\mathrm{GH}$ peak levels during the GARG test, whereas the influence of age $(5 \%$, $p<0.001$ ) was much less dominant.

$>$ Mean peak GH levels were significantly higher in females compared to males $(27.4 \pm 1.73$ $\mathrm{ng} / \mathrm{ml}$ vs. $13.7 \pm 0.95 \mathrm{ng} / \mathrm{ml}, \mathrm{p}<0.0001)$,

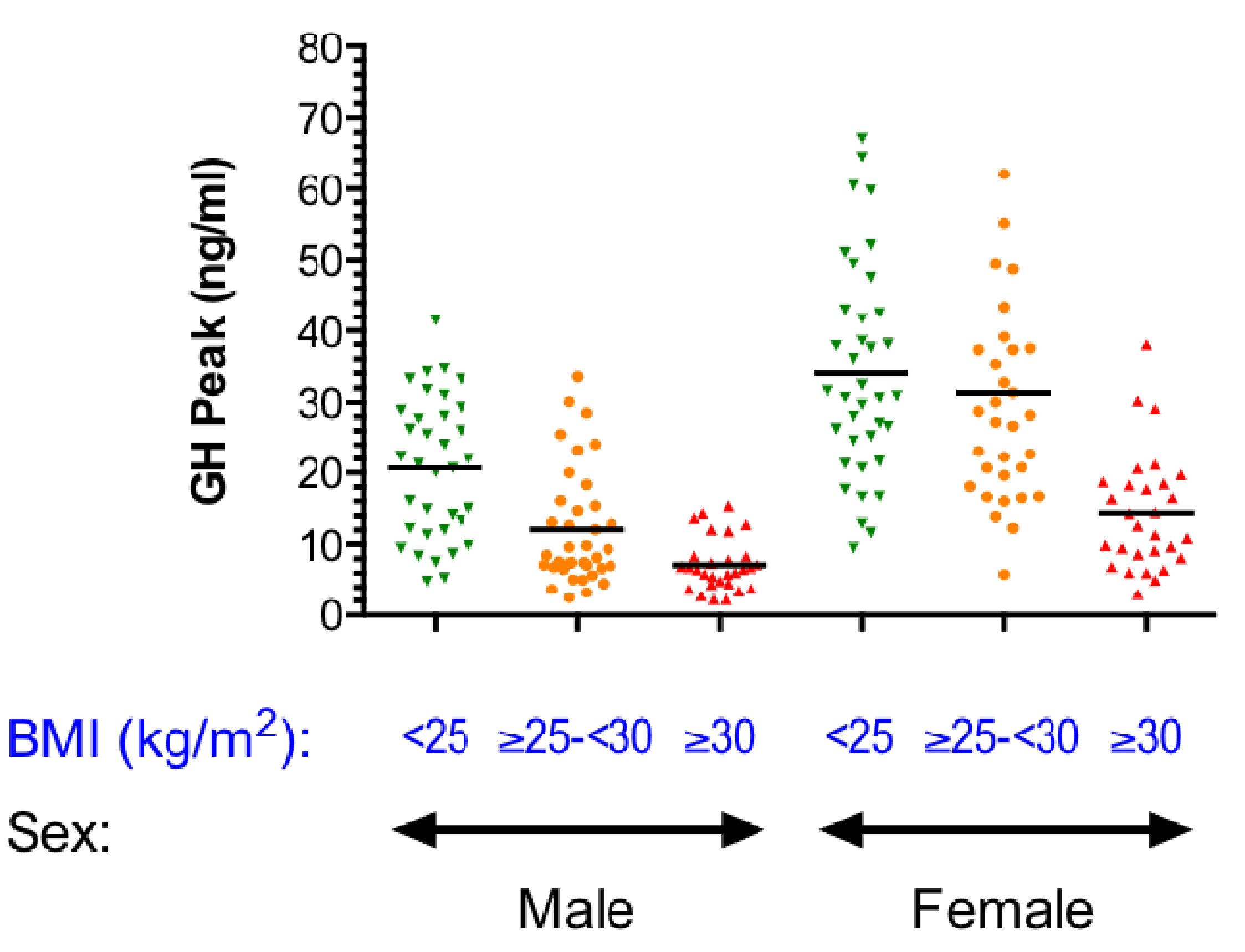

Fig. 1. Figure 1. Peak GH levels during the GARG test in 200 healthy subjects, stratified by sex and BMI. Dark lines represent the means releasing hormone plus arginine; $\mathrm{GH}$, growth hormone.
Furthermore, mean peak $\mathrm{GH}$ levels were higher in lean $(34.1 \pm 2.46 \mathrm{ng} / \mathrm{ml}$ in females v. $20.7 \pm 1.67 \mathrm{ng} / \mathrm{ml}$ in males, $p<0.0001)$ compared to overweight $(31.4 \pm 3.38 \mathrm{ng} / \mathrm{ml}$ in females vs. $12.1 \pm 1.34 \mathrm{ng} / \mathrm{ml}$ in males, $p<0.0001)$ and obese subjects $(14.4 \pm 1.52$ $\mathrm{ng} / \mathrm{ml}$ in females vs. $7.19 \pm 0.68 \mathrm{ng} / \mathrm{ml}$ in males, $p<0.0001$ ) (Figure 1).

Establishment of new cutoffs for peak GH levels during the GHRH plus arginine test by comparison of growth hormone deficient patients and control subjects.

$>$ Considering the significant influence of BMI and sex for the GARG in normal subjects, we aimed to establish diagnostic cutoffs that were adjusted accordingly.

> Comparison of peak $\mathrm{GH}$ levels during the GARG test of patients with GHD to those of a control group (consisting of patients with GHS and healthy subjects) allowed calculation of cutoffs for peak $\mathrm{GH}$ (either as an overall threshold or as BMI-dependent thresholds with at least $95 \%$ specificity for GHD, with the latter being separately provided for both sexes).

As shown in the Table as well as in Figure 2 , the overall cutoff for both sexes was $3.9 \mathrm{ng} / \mathrm{ml}$ (sensitivity $86 \%$ (95\% confidence interval $(\mathrm{Cl})$ $74-94 \%)$, specificity $95 \%(95 \% \mathrm{Cl} 92-98 \%))$; the BMI-adjusted thresholds were $6.5,3.5$, and $2.2 \mathrm{ng} / \mathrm{ml}$ for males, and $9.7,8.5$, and 4.4 $\mathrm{ng} / \mathrm{ml}$ for females (always for lean, overweight, and obese subjects, respectively).
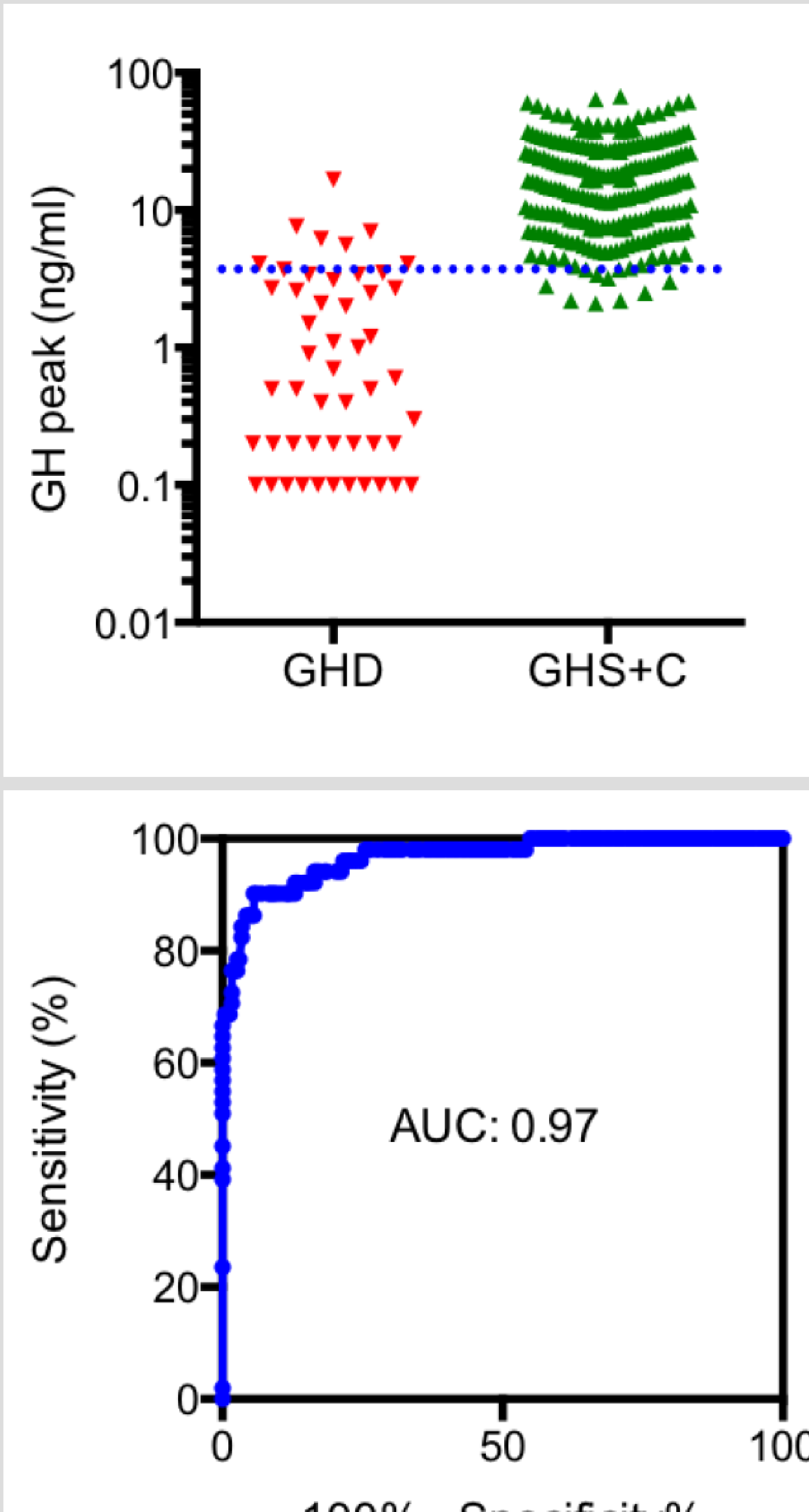

$100 \%$ - Specificity $\%$

Fig. 2. Peak GH levels (top) during GHRH-arginine test and corresponding ROC curve (bottom). The broken line indicates subjects; GHD, growth hormone deficiency; GHS, growt hormone sufficiency.

\begin{tabular}{|c|c|c|c|c|c|c|c|}
\hline & \multirow[b]{2}{*}{ Overall } & \multicolumn{3}{|c|}{ Males } & \multicolumn{3}{|c|}{ Females } \\
\hline & & $\begin{array}{l}\text { Lean } \\
(\mathrm{BMI}<25 \\
\mathrm{kg} / \mathrm{m} 2)\end{array}$ & $\begin{array}{l}\text { Over-weight } \\
(\mathrm{BMI} \geq 25- \\
<30 \mathrm{~kg} / \mathrm{m} 2)\end{array}$ & $\begin{array}{c}\text { Obese } \\
(\mathrm{BMI} \geq 30 \\
\mathrm{kg} / \mathrm{m} 2)\end{array}$ & $\begin{array}{c}\text { Lean } \\
(\mathrm{BMI}<25 \\
\mathrm{kg} / \mathrm{m} 2)\end{array}$ & $\begin{array}{l}\text { Over-weight } \\
\text { (BMI } \geq 25- \\
<30 \mathrm{~kg} / \mathrm{m} 2 \text { ) }\end{array}$ & $\begin{array}{c}\text { Obese } \\
(\mathrm{BMI} \geq 30 \\
\mathrm{kg} / \mathrm{m} 2)\end{array}$ \\
\hline Cutoff (ng/ml) & 3.9 & 6.5 & 3.5 & 2.2 & 9.7 & 8.5 & 4.4 \\
\hline Sensitivity (\%) & 86 & 100 & 92 & 91 & 83 & 100 & 67 \\
\hline Specificity (\%) & 95 & 95 & 96 & 97 & 96 & 97 & 97 \\
\hline ROC AUC & 0.97 & 1.00 & 0.99 & 0.99 & 0.97 & 1.00 & 0.95 \\
\hline p-value & $<0.0001$ & $<0.0001$ & $<0.0001$ & $<0.0001$ & $<0.0005$ & $<0.0001$ & $<0.001$ \\
\hline
\end{tabular}

\section{Conclusions}

We present thresholds for the GHRH-arginine test specific for the new IDS iSYS $\mathrm{GH}$ assay exclusively measuring $22 \mathrm{kD}$ hGH.

The diagnostic accuracy of the GARG test is significantly improved by adjusting thresholds according to sex and BMI.

Both may have important impact on the correct diagnosis in patients with suspicion of GHD. 